\title{
Venous Gas Embolism During Radical Robotic Prostatectomy: A Case Report and Evidence- Based Management Algorithm
}

\author{
Courtney Vidovich ${ }^{1}$, Andres Laserna ${ }^{1}$, Suzanne B. Karan ${ }^{2}$ \\ 1. Anesthesiology and Perioperative Medicine, University of Rochester School of Medicine and Dentistry, Rochester, \\ USA 2. Anesthesiology, University of Rochester, Rochester, USA
}

Corresponding author: Andres Laserna, andres_laserna@urmc.rochester.edu

\begin{abstract}
Robotic-assisted radical prostatectomy (RARP) has gained rapid popularity in the last two decades after early reports of excellent survival rates, quick learning curves, and minimal invasion or tissue damage. Given the anatomical location of surgical prostatectomies and the utilization of intra-abdominal gas during laparoscopy, there is a risk of developing venous air embolism (VAE). We present a case of a 62 -year-old male with hypothyroidism and benign prostatic hyperplasia who underwent robotic suprapubic prostatectomy under general anesthesia. One hour after incision the $\mathrm{ETCO}_{2}$ suddenly dropped (40 $\mathrm{mmHg}$ to $25 \mathrm{mmHg}$ ) as did the $\mathrm{SpO} 2$ (98\% to 90\%). There were no other vital sign changes, nor was there significant blood loss. The surgical team was notified, which prompted the surgeon to inform us that he had just been dissecting around the pelvic venous plexus. At this point, with the clinical suspicion of VAE, abdominal insufflation pressure was lowered, and inspired oxygen was increased to 100\%. After 10 minutes, SpO2 and ETCO2 normalized. A debrief and literature review inspired us to develop a laparoscopic-specific VAE management algorithm, with attention to robotic-case management issues. To the best of our knowledge, this is a rare case report describing a clinical VAE during RARP.
\end{abstract}

Categories: Anesthesiology, Urology

Keywords: venous air embolism, robotic prostatectomy, general anesthesia, iatrogenic complication, adverse event

\section{Introduction}

Robotic-assisted radical prostatectomy (RARP) has gained popularity in the last two decades after early reports of excellent survival rates, quick learning curves, and minimal invasion or tissue damage [1]. Some argue that RARP is the new gold standard for the management of localized prostate cancer citing advantages over open radical retropubic prostatectomy (RRP) and laparoscopic retropubic prostatectomy (LRP) including decreased transfusions and conversions to open surgery, shorter hospital stay, improved one-year continence, and decreased complications when compared specifically to RRP outcomes [2,3].

Review began 08/03/2021 Review ended 08/17/2021 Published 08/19/2021

\section{○ Copyright 2021}

Vidovich et al. This is an open access article distributed under the terms of the Creative Commons Attribution License CC-BY 4.0., which permits unrestricted use, distribution, and reproduction in any medium, provided the original author and source are credited.
Given the anatomical location of surgical prostatectomies and the utilization of intra-abdominal gas during laparoscopy, there is a risk of developing venous air embolism (VAE). While there have been a number of recent cases reporting clinical VAE using a variety of prostatectomy techniques including RRP [4], transurethral resection of prostate (TURP) [5], holmium laser enucleation of the prostate (HoLEP) [6], and greenlight laser photovaporizer (GLPV) [7], to the best of our knowledge, this is a rare case report describing a clinical VAE during RARP.

Appropriate and efficacious management of VAE has previously been outlined [8] and revised [9]. Although these reviews are thorough and provide a comprehensive foundation for VAE prevention and management, there is a need for procedure-specific management algorithms as a reference to provide efficient, proceduretailored, and standardized patient care. After the description of the case report, we present a literature review of VAE management during laparoscopic surgeries and an evidence-based algorithm for the management of VAE during robotic laparoscopies. The patient in our case provided consent for publication of this report.

\section{Case Presentation}

A 62-year-old male with a history significant for medication-controlled hypothyroidism and benign prostatic hyperplasia presented for robotic suprapubic prostatectomy under general anesthesia; the schematic is shown in Figure 1. After uneventful induction and intubation, an arterial line was placed for pulse-pressure-variation (PPV)-targeted fluid administration. The patient was positioned in steep Trendelenburg. One hour after incision, during transection of the pelvic venous plexus, the patient's endtidal carbon dioxide $\left(\mathrm{ETCO}_{2}\right)$ dropped from $40 \mathrm{mmHg}$ to $25 \mathrm{mmHg}$ in a single breath, and oxygen saturation $\left(\mathrm{SpO}_{2}\right)$ decreased from $98 \%$ to $90 \%$. There were no changes in the electrocardiogram, blood pressure, or ventilation, nor was there any concomitant blood loss. The surgical team was notified and decreased 


\section{Cureus}

abdominal insufflation pressures while the patient's inspired oxygen was increased to $100 \%$. After 10 minutes, $\mathrm{SpO}_{2}$ and $\mathrm{ETCO}_{2}$ normalized. As this presentation was highly suspicious for $\mathrm{CO}_{2}$ venous embolism, the emergence plan was modified to exclude the use of nitrous oxide. After tracheal extubation, the patient was transferred to the post-anesthesia care unit where he recovered successfully and was discharged home on the same day.

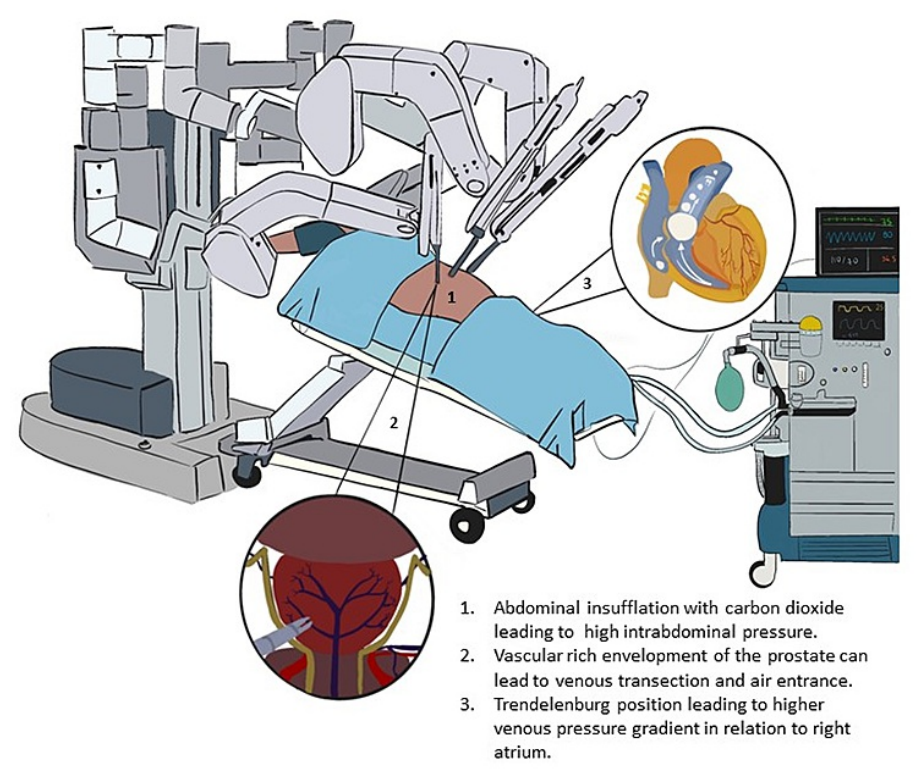

FIGURE 1: Schematic of RARP VAE evolution

RARP, Robotic-assisted radical prostatectomy; VAE, venous air embolism.

\section{Discussion}

We present the successful management of VAE during robotic-assisted prostatectomy characterized by timely identification, proper communication, and adequate support, resulting in no further decompensation. After debriefing and reflecting on the case, we conducted a literature review using Medline and Embase between January 2010 and July 2020. No restrictions on language or publication date were employed, and the terms used were "Prostatectomy," "Robotic prostatectomy," "Laparoscopy," combined with "Air Embolism," "Embolism," " $\mathrm{CO}_{2}$ embolism," excluding the word "embolization." Our inclusion criteria were articles in which VAE was considered or discussed. Two authors (AL and CV) independently screened citations from the initial search using a two-step approach in which first the title and then the abstracts were screened for eligibility using the software Abstrackr (Brown University, School of Public Health, Providence, USA) [10]. For citations that were considered potentially relevant, the full text was retrieved and further screened for eligibility. In cases of disagreement, both reviewers discussed and achieved consensus, and consulted with the third author (SK) to include or exclude articles. After a full-text review and data extraction, we developed a management algorithm for VAE during robotic laparoscopies.

We extracted 37 articles largely comprised of review articles and case reports (Figure 2). 


\section{Cureus}

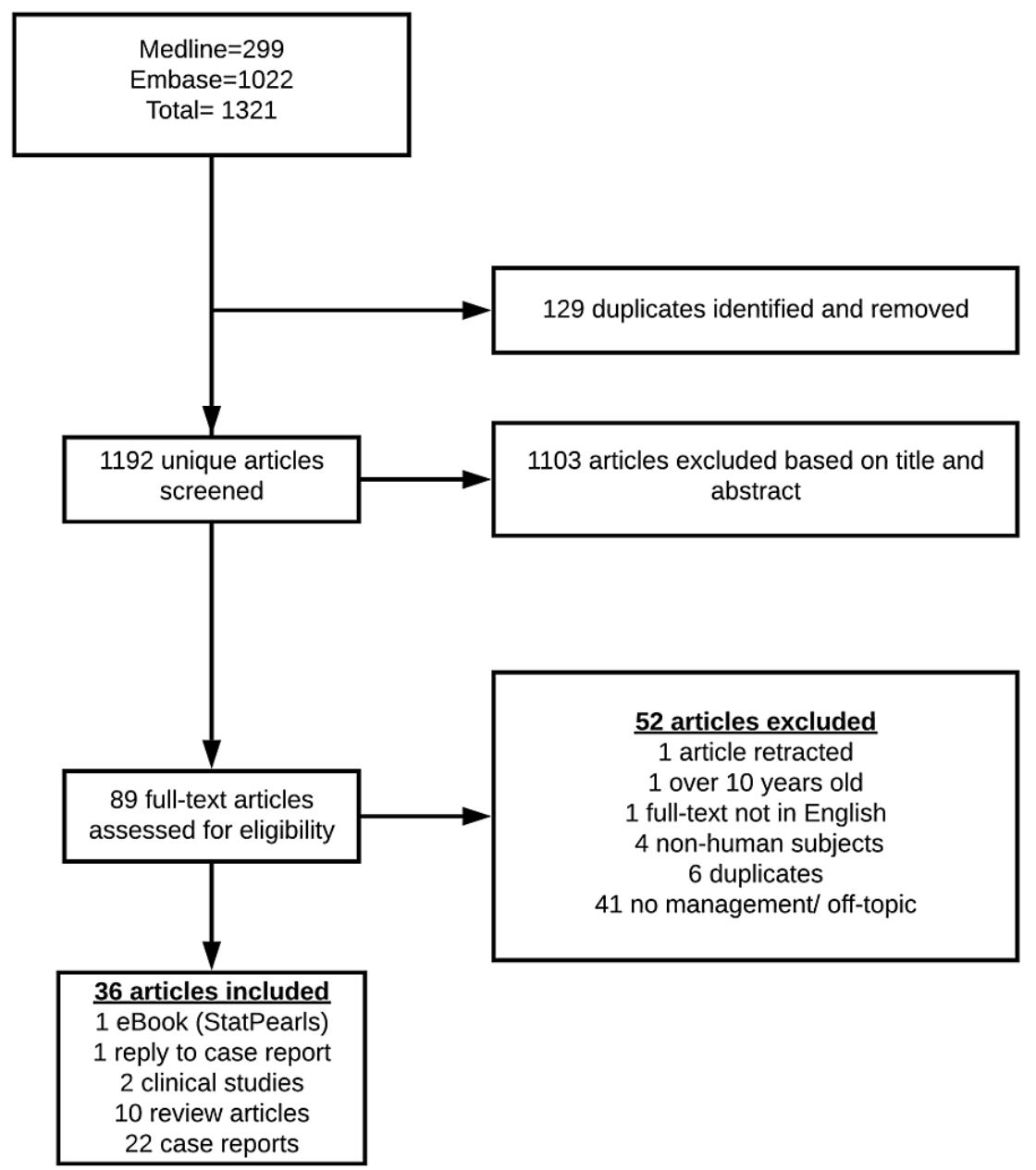

\section{FIGURE 2: Literature review of VAE and RARP case management}

RARP, Robotic-assisted radical prostatectomy; VAE, venous air embolism.

These articles originate from around the world and include 11 from the United States; five from Japan; four from Korea; three each from Australia and Italy; two each from China, India, and Turkey; and one each from Denmark, Singapore, Spain, the Netherlands, and the United Kingdom. All 37 articles consider VAE management during laparoscopic procedures and include four robotic laparoscopies.

\section{Risk of VAE and pathophysiology}

We did not find any published reports of VAE occurring during RARP. Although the risk of a clinically significant VAE is considered rare, it has been a well-established risk of laparoscopic surgeries with a high reported mortality rate of $28 \%[8,9,11]$. Subclinical VAEs diagnosed with transesophageal echocardiogram (TEE) have been reported at an incidence of $17 \%-38 \%$ [12]. This risk of VAE and its effect on morbidity and mortality are dependent on the rate and volume of air accumulation, which varies by degree of vasculature exposed and the pressure gradient between the exposed venous system and the right heart [8,9,13-15].

The degree of vasculature exposed to air varies by procedure. For prostatectomies, the vascular-rich envelopment of the prostate increases the level of risk even with the minimally invasive RARP approach [16] with one study reporting $100 \%$ of subclinical embolic events during RARP occurring during transection of the deep dorsal venous complex [12]. The most commonly reported risk factor, gas insufflation, was mentioned in $73 \%$ of the case reports reviewed [6,7,9,17-30]. The schematic in Figure 1 highlights several of these risks.

\section{Intraoperative diagnosis}

While the application of the American Society of Anesthesia-guided monitoring is the standard for such 
procedures $[9,17,18]$, it has been noted to be equally essential that this monitoring be paired with a vigilant anesthesiologist $[8,9,19,20]$.

The diagnosis of VAE in anesthetized patients mostly presents as tachyarrhythmia, right heart strain, hypotension, decreased end-tidal carbon dioxide and oxygen saturation, and, in severe cases, neurologic sequelae that in most cases are masked until the postoperative period [8,9]. Furthermore, the presentation of VAE varies by size and rate, making its detection challenging, though adverse signs and symptoms have been elucidated based on the size of air entrainment $[8,17]$.

Though TEE is a highly sensitive technique used for the diagnosis of VAE with a detection capability of 0.02 $\mathrm{ml} / \mathrm{kg}$ of entrained air, it is invasive, expensive, and requires expertise [8,21]. Pulmonary artery catheterization has been used to detect air emboli of $0.25 \mathrm{ml} / \mathrm{kg}$, although placement without other indications may cause more risk than warranted [8]. The use of a precordial Doppler ultrasound is highly sensitive in detecting emboli as small as $0.05 \mathrm{ml} / \mathrm{kg}$, most cost-effective, easy to use, and least invasive $[8,22]$. Auscultation of a "mill-wheel" murmurs over the precordium rules in VAE [18]. Even with these options, these technologies used as a tool for VAE detection were referenced in $47 \%$ of case reports $[9,14,23$ 31].

\section{Management: communication and robotic considerations}

Communication with the perioperative team improves the timely anticipation of high-risk VAE portions of surgery [8]. If VAE is suspected by the anesthesiologist, it is imperative to inform the surgeon and start maneuvers such as flooding the exposed vasculature with saline and decreasing insufflation pressure. While flooding the surgical field is effective, it was not mentioned as a common practice in the laparoscopic case reports $[9,19,28,32,33]$.

Decreasing insufflation pressures is more commonly described, likely due to ease of implementation $[6,7,9,20,26,28-30,32-39]$. While these maneuvers are both effective, hemodynamic support is simultaneously managed by the anesthesiologist with concomitant administration of intravenous fluids, vasopressors, and $100 \%$ oxygen to maximize the patient's respiratory mismatch $[6,7,9,17,18,20,23-25,28,29,32,33,36-38,40-46]$. Avoidance of nitrous oxide was more likely to be recommended if patient risk factors were already present, like a patent foramen ovale, as a way to lessen the likelihood of increasing the size of entrained air $[8,9,40]$.

Maneuvers that encourage the release of the air from the right ventricular outflow tract are debatable [19] but still recommended [8,17,41]. These maneuvers, most notably the Trendelenburg or Durant maneuver (Trendelenburg plus partial left lateral decubitus position), were reported in 69\% of case reports reviewed and were considered in most review articles $[9,14,17,18,20,23,24,28,29,33,35,37-39,42,43]$.

The use of Trendelenburg position for its effect on VAE risk has a controversial history [19]; though, it has been shown to increase the pressure in the right atrium and balance the inward pressures of insufflation [13]. Hong et al. hypothesized that this mechanism is a contributory factor to the low rate of VAE in RARP with a steep Trendelenburg angle of 30 degrees, opposed to the typical 15 degrees used in gynecologic surgeries [42]. As the performance of these maneuvers during robotic laparoscopies is not possible due to the patient's fixed position, it was excluded in the accompanying algorithm (Figure 3). 


\section{Cureus}

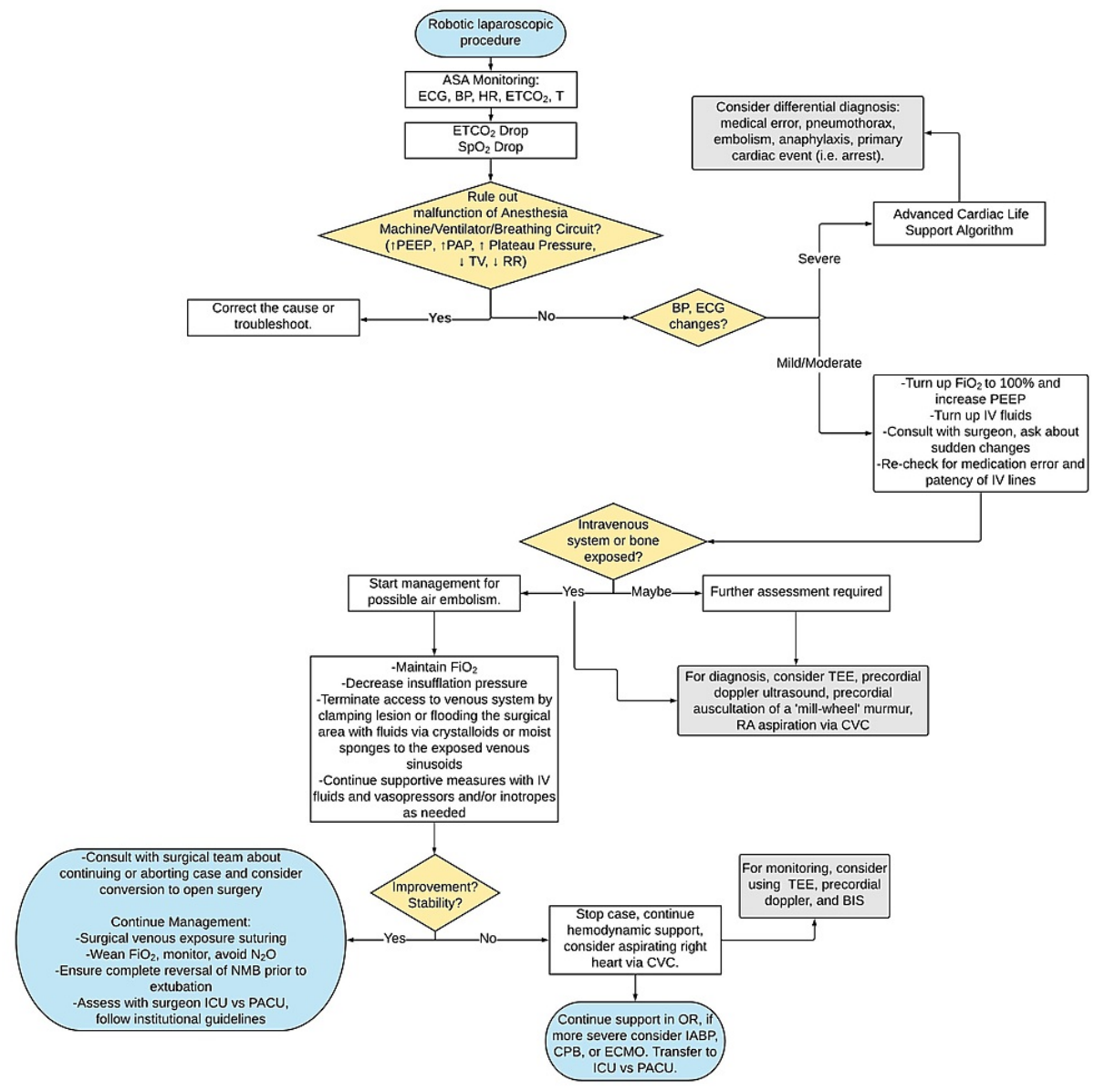

\section{FIGURE 3: Management algorithm for VAE during RARP}

RARP, Robotic-assisted radical prostatectomy; VAE, venous air embolism.

Air aspiration from the right atrium via pulmonary artery catheter is also a debated intervention. While it has been reported that $50 \%$ of entrained air can be aspirated, most studies find this treatment inconsistent in efficacy [46-48]. Further, inserting a catheter solely for the purpose of aspiration has been suggested as controversial due to its risk and low yield [17]. Current recommendations are strongest for its use in hemodynamically unstable patients who have a catheter in situ and are refractory to other management interventions $[8,9,17]$. This review found that $39 \%$ of case reports attempted to aspirate the right atrium for air; successful aspirations also note the beneficial diagnostic ability of this procedure $[23,25,28$ $30,34,37,44,45]$. Figure 3 compiles our results in a patient care algorithm. Article characteristics and descriptions are presented in Table 1 .

\begin{tabular}{|c|c|c|c|c|}
\hline $\begin{array}{l}\text { Lead } \\
\text { Author } \\
\text { (Year) }\end{array}$ & Country & $\begin{array}{l}\text { Type of } \\
\text { Article }\end{array}$ & Patient Characteristics & $\begin{array}{l}\text { Case Management or Suggested } \\
\text { Management }\end{array}$ \\
\hline $\begin{array}{l}\text { Kato et al. } \\
\text { (2015) [6] }\end{array}$ & Japan & Case Report & $\begin{array}{l}\text { A 76-year-old man underwent laparoscopic } \\
\text { transurethral holmium laser enucleation of the } \\
\text { prostate. Unknown if surgery was completed after } \\
\text { VAE. He was discharged on POD } 8 \text { with no } \\
\text { sequelae. }\end{array}$ & $\begin{array}{l}\text { Stopped causal agent, } 100 \% \\
\text { oxygen and pharmacologic agents } \\
\text { given to maintain hemodynamics. } \\
\text { IABP placed for support during ICU } \\
\text { recovery. }\end{array}$ \\
\hline $\begin{array}{l}\text { Lee and } \\
\text { Vazquez } \\
\text { (2015) [7] }\end{array}$ & USA & Case Report & $\begin{array}{l}\text { A 73-year-old male with no known cardiovascular } \\
\text { history and benign prostatic hypertrophy } \\
\text { underwent greenlight laser photoselective } \\
\text { vaporization of the prostate for bladder outlet } \\
\text { obstruction. Unclear if surgery was completed } \\
\text { after VAE. The patient was discharged on POD } 1 \\
\text { without sequelae. }\end{array}$ & $\begin{array}{l}100 \% \mathrm{O}_{2} \text { given, terminated } \\
\text { insufflation, and LMA switched to } \\
\text { ET tube for respiratory support. }\end{array}$ \\
\hline
\end{tabular}




\section{Cureus}

Park et al. Korea Review N/A
(2012) [9]

Hong et al.

(2010) [12]

Korea

Clinical

Study:

Retrospective

43 patients with ASA status of I or II scheduled for elective RALRP enrolled between June 2007 and November 2007. Patients with esophageal disease were excluded due to contraindications with TEE. Two patients enrolled were excluded due to failure of TEE insertion. No patients had PFO or cardiac shunt.

\begin{tabular}{|c|c|c|}
\hline $\begin{array}{l}\text { de Jong et } \\
\text { al. (2019) } \\
{[14]}\end{array}$ & $\begin{array}{l}\text { The } \\
\text { Netherlands }\end{array}$ & Review \\
\hline $\begin{array}{l}\text { Gainsburg } \\
\text { et al. (2012) } \\
\text { [15] }\end{array}$ & USA & Review \\
\hline $\begin{array}{l}\text { Orhurhu et } \\
\text { al. (2020) } \\
{[17]}\end{array}$ & USA & eBook \\
\hline
\end{tabular}

Takechi et al. (2020) [18]

Japan

Case Report hemihepatectomy for intrahepatic

cholangiocarcinoma. Surgery was completed after VAE. The patient was discharged without further complications.

A 67-year-old female with a history of laparoscopic cholecystectomy underwent laparoscopic liver resection for hepatocarcinoma.

De Cassai et al. (2019) [19]

Italy

Case Report

Surgery was completed following VAE. The patient was transferred to the ICU and was discharged on POD 3 without further complications.

A 44-year-old female with a history of severe supravalvular aortic stenosis with surgical repair at 24 years, atrial fibrillation without anticoagulation, and persistent left SVC

Kale et al. (2019) [20]
Case Report underwent laparoscopic robotic rectopexy for recurrent rectal bleeding secondary to rectal prolapse. The surgery was converted to laparotomy and completed following VAE. Further course not mentioned.

A 5-day-old term male with a history of bladder outlet obstruction with anhydramnios requiring cystocentesis, multiple amniocenteses with
Diagnosis with TEE, precordial Doppler, $\mathrm{ETCO}_{2}$ changes, and/or precordial or esophageal stethoscope 'mill-wheel' murmur. Stop insufflation, give $100 \% \mathrm{O}_{2}$, discontinue nitrous oxide, hyperventilate. Give IV fluids, perform Durant maneuver, continuous assessment of vitals with pharmacologic agents to manage hemodynamics. Consider IABP or CPB.

TEE detects subclinical VAE in $17.1 \%$ of laparoscopic radical prostatectomies.

Terminate pneumoperitoneum, Durant maneuver, aspirate RA for air with CVC or PA catheter. CPR if needed.

Close coordination between anesthesiologists and surgeons.

Immediate communication with the surgical team, terminate insufflation, Durant maneuver, hyperventilation with $100 \% \mathrm{O}_{2}$, manage hemodynamics with pharmacologic agents. Attempt aspiration with CVC for high-risk scenarios.

Ventilated at $100 \% \mathrm{O}_{2}$, reduced pneumoperitoneum, and given pharmacologic agents for hemodynamic support. Trendelenburg position was performed and high PEEP was given.

Pneumoperitoneum reduced, PEEP raised, and lesion clamped. Conversion not indicated. Aspiration performed.

Communicated with the surgical team, stopped insufflation, and pharmacologic agents are given to support hemodynamics. IV fluids are given, and an internal jugular catheter was inserted. TEE probe used to investigate. Aspiration of gas attempted. Durant maneuver performed. CPB considered.

Communicated with surgeons and 


\section{Cureus}

\begin{tabular}{|c|c|c|c|}
\hline $\begin{array}{l}\text { DiChiacchio } \\
\text { et al. (2018) } \\
\text { [21] }\end{array}$ & USA & Case Report & $\begin{array}{l}\text { amnioinfusion, and placement of both } \\
\text { vesicoperitoneal and vesicoamniotic shunts } \\
\text { underwent a laparoscopic peritoneal dialysis } \\
\text { catheter placement for worsening renal function. } \\
\text { The patient was placed on ECLS and transferred } \\
\text { to the NICU. The patient expired after } \\
\text { withdrawing ECLS, per the mother's request. }\end{array}$ \\
\hline $\begin{array}{l}\text { Harnsberger } \\
\text { et al. (2018) } \\
\text { [22] }\end{array}$ & USA & Case Report & $\begin{array}{l}3 \text { of } 80 \text { patients who underwent a transanal total } \\
\text { mesorectal excision had a VAE from December } \\
2014 \text { to March } 2018 \text { at a single institution. No } \\
\text { intraoperative or postoperative sequelae were } \\
\text { reported including arrhythmia, myocardial } \\
\text { infarction, stroke, or death. These surgeries were } \\
\text { completed without conversion to open. }\end{array}$ \\
\hline $\begin{array}{l}\text { Basaran et } \\
\text { al. (2016) } \\
{[23]}\end{array}$ & Turkey & Case Report & $\begin{array}{l}\text { An } 8.5-k g \text { 13-month-old female with Trisomy } 21 \\
\text { and pectus carinatum underwent laparoscopic } \\
\text { Morgagni Hernia Repair with a known PFO. The } \\
\text { surgery was completed after VAE. The patient } \\
\text { was discharged on POD } 2 \text { without sequelae. }\end{array}$ \\
\hline $\begin{array}{l}\text { Tognon et } \\
\text { al. (2014) } \\
\text { [24] }\end{array}$ & Italy & Case Report & $\begin{array}{l}\text { A 12-year-old female, previously diagnosed and } \\
\text { treated for Hodgkin Lymphoma, underwent a } \\
\text { laparoscopic lymph node biopsy for suspected } \\
\text { reoccurrence. Surgery was completed after VAE. } \\
\text { The patient was transferred to the PICU and was } \\
\text { discharged on POD } 7 \text { without sequelae. }\end{array}$ \\
\hline $\begin{array}{l}\text { Olsen et al. } \\
\text { (2013) [25] }\end{array}$ & Australia & Case Report & $\begin{array}{l}\text { A 3.14-kg term 3-day-old male underwent a } \\
\text { laparoscopic duodenoduodenostomy for } \\
\text { duodenal atresia, with preoperative } \\
\text { echocardiogram confirming small PDA with left to } \\
\text { right flow and PFO. The procedure was } \\
\text { abandoned, and the patient was transferred to } \\
\text { NICU. On POD } 7 \text {, the patient was extubated, and } \\
\text { the surgery was attempted again. No sequelae at } \\
\text { discharge on POD } 15 \text { and is meeting } \\
\text { developmental milestones at } 19 \text { months of age. }\end{array}$ \\
\hline
\end{tabular}

DiChiacchio

et al. (2018) [21]

Harnsberger

et al. (2018) [22]

Basaran et

al.

[23]

Tognon et

al. (2014)

[24]

\section{Vora et al.}

(2013) [26]

India

Case Report

A 35-year-old female underwent a transperitonea laparoscopic Boari's ureteric reimplantation. Surgery was abandoned after VAE. The patient was transferred to ICU and regained consciousness 2 hours post-op. She was discharged without any neurological deficit.

A 72-year-old male without significant past medical history underwent elective laparoscopic Shen et al. (2011) [27]

Case Report

Smith et al. (2011) [28] right kidney resection. Surgery was completed after VAE, and the patient recovered without any sequelae.

A 34-year-old female underwent suction D\&C followed by a laparoscopic procedure to examine her uterus. Surgery was completed after VAE; the patient was discharged home without any longterm adverse events. stopped pneumoperitoneum. CPR performed. Aspiration of air embolism was attempted. Durant maneuver performed. Supported on ECMO.

Stopped insufflation and given hemodynamic support with fluids and pharmacologic agents. Durant maneuver performed.

Preventative management for patients with known PFO includes keeping intra-abdominal pressure under $12 \mathrm{mmHg}$, use of TEE, and avoiding nitrous oxide for suspected VAE.

Insufflation stopped. Durant maneuver performed. Aspirated via CVC. CPR was administered with $100 \% \mathrm{O}_{2}$ and pharmacologic agents.

Pneumoperitoneum stopped. chest compressions, pharmacologic agents, and $100 \% \mathrm{O}_{2}$ given. The patient was placed in Trendelenburg.

Pneumoperitoneum released, placed in Trendelenburg, fluids and pharmacologic agents administered to maintain hemodynamics. Auscultation of precordial region was without 'millwheel' murmur. $\mathrm{FiO}_{2}$ increased to 100\%. CPR given. Unsuccessful RA aspiration via CVC.

Precordial auscultation revealed splashing 'mill-wheel' murmur. Aspirated RA via CVC.

Pneumoperitoneum was terminated.

$100 \%$ oxygen given, stopped insufflation, aggressive fluid resuscitation, and pharmacologic agents given to manage hemodynamics. Durant maneuver performed. The laparoscopic procedure was aborted.

Diagnose, stop insufflation, alert surgical staff, manage hemodynamics with pharmacologic 


\section{Cureus}

Sandadi et

al. (2010)

USA

Review

[29]

Brull et al.

(2017) [30]

USA

Review

N/A

Mills et al.

(2011) [31]

UK

Review

N/A
A 65-year-old male with prostate cancer underwent a laparoscopic prostatectomy. Surgery

Seong et al. (2010) [35] Korea Case Report completed following VAE. Transferred to the ICU and discharged on POD 10 without any related complications.

A 43-year-old male, with mild hypertension and thyroiditis, underwent an elective retroperitoneoscopic right adrenalectomy for an Sollazzi et al. (2011) Italy Case Report [36]

Burcharth et

al. (2012) Denmark Case Report [37]

Kawahara et

al. (2017) Japan Case Report
adrenal 'incidentaloma'. Surgery completed after VAE. Post-op patient was transferred to ICU. With an uneventful surgical course, he was discharged home POD 7.

A 50-year-old female without notable medical history underwent laparoscopic cholecystectomy and liver cyst fenestration. VAE occurred immediately after surgery was completed. The patient was transferred to another hospital for post-op care and was discharged on POD 14 without any sequelae.

A 60-year-old male with hypertension and postlaparoscopic cholecystectomy underwent laparoscopic liver resection for hepatocellular carcinoma. Paradoxical VAE occurred with the absence of right-to-left systemic shunt. Surgery was completed after conversion to open laparotomy. Post-operatively, the patient was transferred to the ICU, went into a coma, and suffered quadriplegia. The patient was discharged to rehabilitation with severe neurologic sequelae remaining 6 months post-op. agents, give $100 \% \mathrm{O}_{2}$, and place in Trendelenburg position. If stable, discuss continuing surgery or converting to open procedure. If still unstable, call the cardiac arrest team, give CPR, and insert the right atrial catheter for gas aspiration.

Early action, terminate the source of air, stop communication between atmosphere and vessel, give high flow $100 \% \mathrm{O}_{2}$. Perform aspiration via CVC only if already in place, low yield if the sole purpose for placement is aspiration. Perform Durant maneuver, CPR, and additional resuscitation therapy including the use of pharmacologic agents and ECMO.

Management includes careful monitoring of $\mathrm{ETCO}_{2}$. If $\mathrm{VAE}$ is suspected, infuse fluids rapidly, give $100 \% \mathrm{O}_{2}$, and inform the surgeon who should prevent further air entering. Aspirate if the line is in situ. Consider using TEE and Doppler techniques to monitor.

Ventilated with $100 \% \mathrm{O}_{2}$, stopped insufflation, IV fluids, and pharmacologic agents given, placed in Durant's position, aspiration via CVC. TEE and CXR are used for evaluation. Converted to open surgery and recovered in the ICU.

Durant maneuver performed. $100 \%$ $\mathrm{O}_{2}$, pharmacologic agents, and IV fluids are given. TEE used.

Precordial Doppler ultrasound confirmed VAE. Durant maneuver was performed, $100 \% \mathrm{O}_{2}$ given, CVC line placed, and air was aspirated.

TEE is used to show air in left atrium and left ventricle. BIS monitoring was introduced to evaluate brain activity after VAE was suspected to develop into a paradoxical $\mathrm{CO}_{2}$ embolism. The venous opening was closed, and surgery was converted to laparotomy. 


\section{Cureus}

Lee et al. Singapore Case Report
(2019) [39]

Abraham et

al. (2018) India Case Report
$[40]$

Russell et

al. (2018)

[41]
Reply to

Case Report chronic renal impairment, dyslipidemia underwent elective laparoscopic liver resection for Childs A liver cirrhosis from hepatitis B complicated by hepatocellular carcinoma. Surgery was resumed after VAE with two more episodes of embolism. After completion, the patient recovered in the ICU, complicated by pneumonia. He was discharged 2 weeks post-op without other sequelae.

A 23-year-old female with previous endoscopic trans-sphenoidal radical excision for Cushing's syndrome underwent bilateral adrenalectomy via retroperitoneoscopy. Surgery was successfully completed after VAE. She was transferred to the ICU and was discharged without related sequelae on POD 4.

N/A
Taylor et al. (2010) [42]

USA

Case Report

et al. (2013) Spain

[43]

Case Report

A 58-year-old male underwent laparoscopic left hemicolectomy for tumor in the colon. The surgical procedure was suspended after VAE. Case conclusions were not reported.

A 52-year-old female underwent laparoscopic nephrectomy. Surgery was converted to open procedure and was completed after VAE. The

Yu and

Fang (2014) China [44]

Case Report patient was transferred to the ICU with mechanical ventilation support for pulmonary edema. The patient was extubated on POD 3 and was discharged without any sequelae on POD 11.

Clinical Patients with ASA physical status I or II

Hong et al. (2010) [47]

\section{Korea Study:}

Retrospective Study undergoing RALRP $(n=26)$ or RRP $(n=26)$ were enrolled from March 2007 to November 2007. One
patient was excluded due to TEE insertion failure.

Yamashita and Nishida (2016) [49]

Japan

Review

N/A

Shiraishi et

al. (2018)

Japan

Review

N/A
Communicated with the surgical team, pneumoperitoneum terminated, and placed on $100 \%$ $\mathrm{O}_{2}$ with pharmacologic agents given to support hemodynamics. VAE confirmed by aspiration of RA with CVC. Precordium auscultation found 'mill-wheel' murmur.

Communicated with surgeon, $\mathrm{FiO}_{2}$ increased to $100 \%$, and

Durant maneuver was performed. Aggressively treated with fluids and pharmacologic agents. Aspiration via CVC was successful. Surgery completed.

Stop insufflation, perform Durant maneuver, give $100 \% \mathrm{O}_{2}$ with

aggressive volume expansion and pharmacologic agents for hemodynamic support. CPR as needed and if severe, consider aspiration. Discuss the decision to continue by surgeon and anesthesiologist.

CPR was performed, and pharmacologic agents are given for hemodynamic control. Other etiology is ruled out.

Fluids given. Rule out other etiologies. Pharmacologic agents are given to maintain hemodynamics. Surgical procedure suspended. CT ruled out pulmonary embolism and DVT. VAE was diagnosed by exclusion.

Insufflation discontinued. Trendelenburg maneuver performed followed by CPR with pharmacologic agents given to maintain hemodynamics. TEE confirmed VAE.

TEE can be used to detect subclinical VAE during RALRP at $38 \%$ and RRP at $80 \%$.

Close coordination among the surgeons, anesthesiologists, and other medical staff.

The key is prevention and early identification of $\mathrm{CO}_{2}$ embolism with active and effective symptomatic treatment including reducing pneumoperitoneum and using TEE 


\section{Cureus}

Eser et al. (2016) [51] Turkey N/A

N/A as a sensitive way to monitor VAE. Release pneumoperitoneum and stop insufflation. Perform Durant maneuver. Aggressive volume expansion or aspiration by insertion of CVC may be attempted.

Release pneumoperitoneum. Exclude alternative etiologies including a cardiac event, anaphylaxis, or intra-abdominal hemorrhage.

\section{TABLE 1: Literature review of VAE during laparoscopy}

VAE, Venous air embolism; IABP, intra-aortic balloon pump; LMA, laryngeal mask airway; ET, endotracheal; CPB, cardiopulmonary bypass; ASA, the American Society of Anesthesiologists; RALRP, robot-assisted laparoscopic radical prostatectomy; PFO, patent foramen ovale; RA, rheumatoid arthritis; CVC, central venous catheter; CPR, cardiopulmonary resuscitation; PEEP, positive end-expiratory pressure; SVC, superior vena cava; ECLS, Extracorporeal Life Support Program; NICU, newborn intensive care unit; PICU, pediatric intensive care unit; PDA, patent ductus arteriosus; $\mathrm{BIS}$, bispectral index.

Based on our case and a literature review, we developed a management algorithm for use when clinical VAE presents during robotic laparoscopies. This algorithm presents key decision points driving appropriate and validated monitoring and management addressing exposure risks of venous systems and assessing improvement versus stability. Ultimately, this algorithm is designed to work in synergy with a working knowledge of VAE physiology, diligent monitoring, and open communication among the perioperative team.

The management of carbon dioxide embolism has been previously described [8], amended with a laparoscopy focus [9], and revised in 2017 [17]. In comparing the case report management practices to what was covered in these reviews, most were consistent with management guidelines; however, there were some expected variations. Consistent practices among case reports included the use of $\mathrm{ETCO}_{2}$ and $\mathrm{SpO}_{2}$ as primary indicators of VAE, termination of insufflation, use of $100 \%$ oxygen, and maintenance of hemodynamics with intravenous pharmacologic agents and fluids. In contrast, the application of more sensitive VAE detection technology like precordial Dopplers was under-utilized, although actual appropriateness is difficult to evaluate. The intervention of air aspiration was used in about half of the case reports. This inconsistency could be due to the perceived risk versus benefit involved in inserting the central catheter or that the embolic event resolved before the intervention was able to be applied.

Most cases and reviews do not comment on the importance of adequate communication as part of a treatment algorithm. While it is conceivable that proper communication is so commonplace that it is not considered a necessary step to mention, it is nonetheless harmless and imperative to optimal patient safety, cannot be understated, and is thus included in our management algorithm. In the same vein, the decision to continue or abort surgery also lacks commentary in the literature. It seems intuitive that these decisions are considered and risks stratified by the anesthetic and surgical teams as per patient stability. A specific approach to preventative mechanisms to avoid a second VAE during these cases is also not generally addressed in the articles reviewed.

Finally, post-procedural management is an important component to complete any patient care algorithm. While the detection of neurological sequelae is an important aspect to continued post-anesthetic care, some highlight the importance of monitoring right heart failure post-operatively [9] with others underscoring the importance of mitigating the VAE effect on right ventricular afterload as a precursor to causing heart failure [8].

Future research would benefit from validating our presented algorithm in managing VAE during RARP. Specific areas that merit further illumination include decision support to guide continuing or aborting surgery and VAE-specific post-procedure monitoring and support. Barriers to using supplemental monitoring, like precordial Doppler ultrasound, should be further evaluated to best understand their lack of widespread use.

\section{Conclusions}

In conclusion, we report successful management of VAE during robotic-assisted laparoscopic prostatectomy. Upon debriefing, we identified the lack of an adequate management algorithm, given the constraint from using the robot and accompanying patient position. VAE identification is challenging, and severe sequelae can occur suddenly and rapidly. Reviewing the literature to date, we provide an updated patient care 
algorithm in an effort to promote a standardize approach to VAE management during robotic-assisted laparoscopic procedures.

\section{Additional Information \\ Disclosures}

Human subjects: Consent was obtained or waived by all participants in this study. Conflicts of interest: In compliance with the ICMJE uniform disclosure form, all authors declare the following: Payment/services info: All authors have declared that no financial support was received from any organization for the submitted work. Financial relationships: Suzanne Karan declare(s) a grant from NIH 1UG3HL140177-01A1. Site investigator on study 1/2: An Anesthesia-Centered Bundle to Reduce Postoperative Pulmonary Complications: The PRIME-AIR Study. The patient referred to in this manuscript is and was not enrolled in the PRIME-AIR study. . Other relationships: All authors have declared that there are no other relationships or activities that could appear to have influenced the submitted work.

\section{Acknowledgements}

The authors thank Daniela Martinez for her artistic contribution in developing the figures in this article.

\section{References}

1. Ficarra V, Cavalleri S, Novara G, Aragona M, Artibani W: Evidence from robot-assisted laparoscopic radical prostatectomy: a systematic review. Eur Urol. 2007, 51:45-55. 10.1016/j.eururo.2006.06.017

2. Hakenberg OW: A brief overview of the development of robot-assisted radical prostatectomy . Arab J Urol. 2018, 16:293-6. 10.1016/j.aju.2018.06.006

3. Luciani LG, Mattevi D, Mantovani W, et al.: Retropubic, laparoscopic, and robot-assisted radical prostatectomy: a comparative analysis of the surgical outcomes in a single regional center. Curr Urol. 2017, 11:36-41. 10.1159/000447192

4. Memtsoudis SG, Malhotra V: Catastrophic venous air embolus during prostatectomy in the Trendelenburg position. Can J Anaesth. 2003, 50:1084-5. 10.1007/BF03018389

5. Matsuno D, Cho S, Isshiki S, Kojima S, Sato N, Suzuki F, Furuya Y: A case of venous air embolism during transurethral resection of the prostate. Hinyokika Kiyo. 2007, 53:409-411.

6. Kato T, Sugimoto M, Matsuoka Y, et al.: Case of vascular air embolism during holmium laser enucleation of the prostate. Int J Urol. 2015, 22:227-9. 10.1111/iju.12651

7. Lee A, Vazquez R: Venous gas embolism caused by fibrin sealant application to the prostate during greenlight laser photoselective vaporization. A A Case Rep. 2015, 4:100-2. 10.1213/XAA.0000000000000138

8. Mirski MA, Lele AV, Fitzsimmons L, Toung TJ: Diagnosis and treatment of vascular air embolism . Anesthesiology. 2007, 106:164-77. 10.1097/00000542-200701000-00026

9. Park EY, Kwon JY, Kim KJ: Carbon dioxide embolism during laparoscopic surgery. Yonsei Med J. 2012, 53:459-66. 10.3349/ymj.2012.53.3.459

10. Wallace BC, Small K, Brodley CE, Lau J, Trikalinos TA: Deploying an interactive machine learning system in an evidence-based practice center: Abstrackr. Proceedings of the 2nd ACM SIGHIT International Health Informatics Symposium. Association for Computing Machinery, Miami, Florida. 2012, 819-824.

11. Cottin V, Delafosse B, Viale JP: Gas embolism during laparoscopy: a report of seven cases in patients with previous abdominal surgical history. Surg Endosc. 1996, 10:166-169. 10.1007/s004649910038

12. Hong JY, Kim WO, Kil HK: Detection of subclinical CO2 embolism by transesophageal echocardiography during laparoscopic radical prostatectomy. Urology. 2010, 75:581-4. 10.1016/j.urology.2009.04.064

13. Kim CS, Kim JY, Kwon JY, Choi SH, Na S, An J, Kim KJ: Venous air embolism during total laparoscopic hysterectomy: comparison to total abdominal hysterectomy. Anesthesiology. 2009, 111:50-4. 10.1097/ALN.0b013e3181a05ac7

14. de Jong KI, de Leeuw PW: Venous carbon dioxide embolism during laparoscopic cholecystectomy a literature review. Eur J Intern Med. 2019, 60:9-12. 10.1016/j.ejim.2018.10.008

15. Gainsburg DM: Anesthetic concerns for robotic-assisted laparoscopic radical prostatectomy . Minerva Anestesiol. 2012, 78:596-604.

16. Albin MS, Ritter RR, Reinhart R, Erickson D, Rockwood A: Venous air embolism during radical retropubic prostatectomy. Anesth Analg. 1992, 74:151-3. 10.1213/00000539-199201000-00027

17. Orhurhu VJ, Gao CC, Ku C: Carbon Dioxide Embolism. StatPearls Publishing, Treasure Island, FL; 2021.

18. Takechi K, Ito M, Peng Y, Daizen W, Shimizu I: Laparoscopic image of carbon dioxide embolism during laparoscopic hepatectomy: a case report. JA Clin Rep. 2020, 6:39. 10.1186/s40981-020-00345-4

19. De Cassai A, Boetto R, Gabellini G, Cillo U: Massive carbon dioxide embolism during laparoscopic liver resection: a case report. Cureus. 2019, 11:e5075. 10.7759/cureus.5075

20. Kale RD, Sarwar MF, Sopchak A: Intraoperative massive carbon dioxide embolism captured with transesophageal echocardiography in a patient with a rare vena cava anomaly. J Cardiothorac Vasc Anesth. 2019, 33:157-61. 10.1053/j.jvca.2018.01.054

21. DiChiacchio L, Cappiello CD, Greenspon J: Extracorporeal cardiopulmonary resuscitation in a neonate after air embolism during insufflation for laparoscopic peritoneal dialysis catheter placement. J Surg Case Rep. 2018, 2018:rjy119. 10.1093/jscr/rjy119

22. Harnsberger CR, Alavi K, Davids JS, Sturrock PR, Zayaruzny M, Maykel JA: CO2 embolism can complicate transanal total mesorectal excision. Tech Coloproctol. 2018, 22:881-5. 10.1007/s10151-018-1897-8

23. Basaran B, Basaran A, Kozanhan B, Özmen S, Basaran M: Simple handling of venous air embolism during abdominal myomectomy. Braz J Anesthesiol. 2016, 66:549-50. 10.1016/j.bjane.2014.02.012

24. Tognon C, De Corti F, Michelon S, Gamba P: Carbon dioxide embolism during laparoscopic lymph-node 
biopsy in a girl: A rare occurence. J Pediatr Surg Case Rep. 2014, 2:377-379. 10.1016/j.epsc.2014.07.002

25. Olsen M, Avery N, Khurana S, Laing R: Pneumoperitoneum for neonatal laparoscopy: how safe is it? . Paediatr Anaesth. 2013, 23:457-9. 10.1111/pan.12146

26. Vora KS, Shah VR, Parikh GP, Modi PR: Successful resuscitation after suspected carbon dioxide embolism during laparoscopic ureteric reconstructive surgery. Indian J Crit Care Med. 2013, 17:190-1. 10.4103/09725229.117081

27. Shen JC, Ji MH, Yang C, Wang X, Yang JJ: Severe carbon dioxide embolism during laparoscopic kidney resection. Acta Anaesthesiol Scand. 2011, 55:505. 10.1111/j.1399-6576.2011.02408.x

28. Smith HJ: Carbon dioxide embolism during pneumoperitoneum for laparoscopic surgery: a case report . AANA J. 2011, 79:371-373.

29. Sandadi S, Johannigman JA, Wong VL, Blebea J, Altose MD, Hurd WW: Recognition and management of major vessel injury during laparoscopy. J Minim Invasive Gynecol. 2010, 17:692-702. 10.1016/j.jmig.2010.06.005

30. Brull SJ, Prielipp RC: Vascular air embolism: a silent hazard to patient safety. J Crit Care. 2017, 42:255-63. 10.1016/j.jcrc.2017.08.010

31. Mills GH: Anaesthesia and the perioperative management of hepatic resection. Trends Anaesth Crit Care. 2011, 1:147-152. 10.1016/j.tacc.2011.01.013

32. Shaikh N, Ummunisa F: Acute management of vascular air embolism. J Emerg Trauma Shock. 2009, 2:180-5. 10.4103/0974-2700.55330

33. Jaffe RA, Siegel LC, Schnittger I, Propst JW, Brock-Utne JG: Epidural air injection assessed by transesophageal echocardiography. Reg Anesth. 1995, 20:152-5.

34. Soriano SG, McManus ML, Sullivan LJ, Scott RM, Rockoff MA: Doppler sensor placement during neurosurgical procedures for children in the prone position. J Neurosurg Anesthesiol. 1994, 6:153-5. 10.1097/00008506-199407000-00001

35. Seong CL, Choi EJ, Song SO: Re-insufflation after deflation of a pneumoperitoneum is a risk factor for $\mathrm{CO}(2)$ embolism during laparoscopic prostatectomy - a case report. Korean J Anesthesiol. 2010, 59 Suppl:S201-6. 10.4097/kjae.2010.59.S.S201

36. Sollazzi L, Perilli V, Punzo G, Ciocchetti P, Raffaelli M, Bellantone R, Lombardi CP: Suspect carbon dioxide embolism during retroperitoneoscopic adrenalectomy. Eur Rev Med Pharmacol Sci. 2011, 15:1478-1482.

37. Burcharth J, Burgdorf S, Lolle I, Rosenberg J: Successful resuscitation after carbon dioxide embolism during laparoscopy. Surg Laparosc Endosc Percutan Tech. 2012, 22:e164-7. 10.1097/SLE.0b013e31825150a9

38. Kawahara T, Hagiwara M, Takahashi H, et al.: Cerebral infarction byparadoxical gas embolism during laparoscopic liver resection with injury of the hepatic vessels in a patient without a right-to-left systemic shunt. Am J Case Rep. 2017, 18:687-91. 10.12659/ajcr.903777

39. Lee YL, Hwang KY, Yew WS, Ng SY: An abnormal capnography trace due to air embolism in the lateral position. BMJ Case Rep. 2019, 12:e231316. 10.1136/bcr-2019-231316

40. Abraham MA, Jose R, Paul MJ: Seesawing end-tidal carbon dioxide: portent of critical carbon dioxide embolism in retroperitoneoscopy. BMJ Case Rep. 2018, 2018:bcr2017219397. 10.1136/bcr-2017-219397

41. Russell JO, Vasiliou E, Razavi CR, Prescott JD, Tufano RP: Letter to the Editor regarding "Carbon dioxide embolism during transoral robotic thyroidectomy: a case report". Head Neck. 2019, 41:830-1. 10.1002/hed.25500

42. Taylor SP, Hoffman GM: Gas embolus and cardiac arrest during laparoscopic pyloromyotomy in an infant . Can J Anaesth. 2010, 57:774-8. 10.1007/s12630-010-9320-6

43. Galipienzo J, Rosado R, Zarza B, Olarra J: Air embolism after deflation of the pneumoperitoneum in fasttrack laparoscopic assisted hemicolectomy. Chin Med J (Engl). 2013, 126:3798.

44. Yu X FX, Fang X: Successful resuscitation after fatal carbon dioxide embolism duing laparoscopic nephrectomy. Chin Med J (Engl). 2014, 127:2863-4.

45. Sibai AN, Baraka A, Moudawar A: Hazards of nitrous oxide administration in presence of venous air embolism. Middle East J Anaesthesiol. 1996, 13:565-571.

46. Tabatabaie O, Kasumova GG, Eskander MF, Critchlow JF, Tawa NE, Tseng JF: Totally implantable venous access devices: a review of complications and management strategies. Am J Clin Oncol. 2017, 40:94-105. 10.1097/COC.0000000000000361

47. Hong JY, Kim JY, Choi YD, Rha KH, Yoon SJ, Kil HK: Incidence of venous gas embolism during roboticassisted laparoscopic radical prostatectomy is lower than that during radical retropubic prostatectomy. $\mathrm{Br} \mathrm{J}$ Anaesth. 2010, 105:777-81. 10.1093/bja/aeq247

48. Muth CM, Shank ES: Gas embolism. N Engl J Med. 2000, 342:476-82. 10.1056/NEJM200002173420706

49. Yamashita C, Nishida O: [Anesthetic Management in Robotic-assisted Laparoscopic Radical Prostatectomy]. Masui. 2016, 65:894-900.

50. Shiraishi T, Nishizawa Y, Yamamoto H, Tsukada Y, Sasaki T, Ito M: Carbon dioxide embolism during transanal total mesorectal excision (taTME). Tech Coloproctol. 2018, 22:735-8. 10.1007/s10151-018-1845-7

51. Eser A, Gümüş İ̇, Akgün N, Yüce E, Kalem MN: The management of gynecological laparoscopic complications: review. Turkiye Klinikleri J Gynecol Obst. 2017, 27:20-30. 10.5336/gynobstet.2015-43687

52. Lam A, Khong SY, Bignardi T: Principles and strategies for dealing with complications in laparoscopy . Curr Opin Obstet Gynecol. 2010, 22:315-9. 10.1097/GCO.0b013e32833bea41 